\title{
Cognitive Content Generation for Healthy Ageing
}

\author{
Yuki Hayashi ${ }^{1, *}$, Akinori Abe ${ }^{2, \dagger}$ \\ ${ }^{1}$ Graduate School of Science and Engineering, Chiba University, Inage-ku, Chiba-shi, Chiba 261-0004, Japan \\ ${ }^{2}$ Faculty of Letters, Chiba University, Inage-ku, Chiba-shi, Chiba 261-0004, Japan
}

\section{ARTICLE INFO}

Article History

Received 17 May 2018

Accepted 11 November 2018

Keywords

Prevention of dementia

shopping activities

Shopping Game

content generation

\begin{abstract}
From the viewpoint of preventing dementia, balanced meal, moderate exercise, intellectual activities and social interaction are important. We considered shopping activities were proper to encourage those factors because the activities were intellectual in human daily activities. In this paper, we are going to construct Shopping Game and discuss how to evaluate the activities in the game from the viewpoint of preventing dementia. In addition, we will discuss content generation in Shopping Game.
\end{abstract}

\section{INTRODUCTION}

Dementia is a general term for a decline in mental ability enough to interfere with daily life. Alzheimer's is the most common type of dementia. Otake [1] pointed out balanced meal, moderate exercise, intellectual activities and social interaction were important from the viewpoint of preventing dementia. In addition, as people get older, physical activities decrease because of retirement, bereavement, and so on [2].

We considered shopping activities were proper to encourage those factors because the activities were intellectual in human daily activities. Shopping activities are one of the daily activities and people should do that usually by themselves. Some people visit a real grocery store and the others use online store or delivery service (e.g., COOP). In addition, convenient stores are visited not only by the young and also by the elderly in Japan [3], so shopping activities are one of the essential daily activities for many people. Therefore, in the situation of shopping activities, we thought we could activate intellectual activities to prevent dementia. In addition, we have to take psychological stress into consideration. One of the solutions is gamification. Gamification is a method which applies some ingredients or ideas in the field of game to the other field [4]. For example, gamification is used for rehabilitation or learning support.

In this paper, we construct Shopping Game and discuss how to evaluate the activities in the game from the viewpoint of preventing dementia. In addition, we will discuss content generation in Shopping Game.

\footnotetext{
*Corresponding author. Email: yu751@outlook.jp

${ }^{+}$Present address: DWANGO Artificial Intelligence Laboratory, Tokyo, Japan
}

(C) 2018 The Authors. Published by Atlantis Press SARL. cense (http://creativecommons.org/licenses/by-nc/4.0/).

\section{METHOD - SHOPPING GAME}

In many researches about consumer behavior [5-7], they usually observe consumers in a real grocery shop. However, this way of observation may be difficult for observers and for participants. Abe said that "The way of observation in my research requires lots of time and labor, so it is difficult to collect lots of shopping activities data." [7]. Accordingly, we developed Shopping Game. In addition, especially in urban areas in Japan, there are many people who do not have any grocery stores around their houses [8]. So online shopping services have also been demanded.

In this game, user can move a character and walk around virtual store (Figure 1). Upper part means a basket which the character has and lower part means a floor in the virtual store. If user wants a particular item, he/she can drag the picture of item from floor to basket. On the other hand, if user stops purchasing an item, he/she can drag the picture of item from basket to floor. There are many areas in the store, for example, vegetables, bakery or snacks. When a character approaches a certain area, user can see information on each item, which information fundamentally consists of name, amount and price.

Participants were 34 people, and 12 of them were house-workers, 11 were boarders and 11 were home-students. They can play the game depending on their purposes. They often told us some comments. So we recorded their activities and utterances.

\section{RESULTS}

As shown in Figure 2, participant (A) has a stickle preference to a specific item (milk-X). You can see that the specific item 


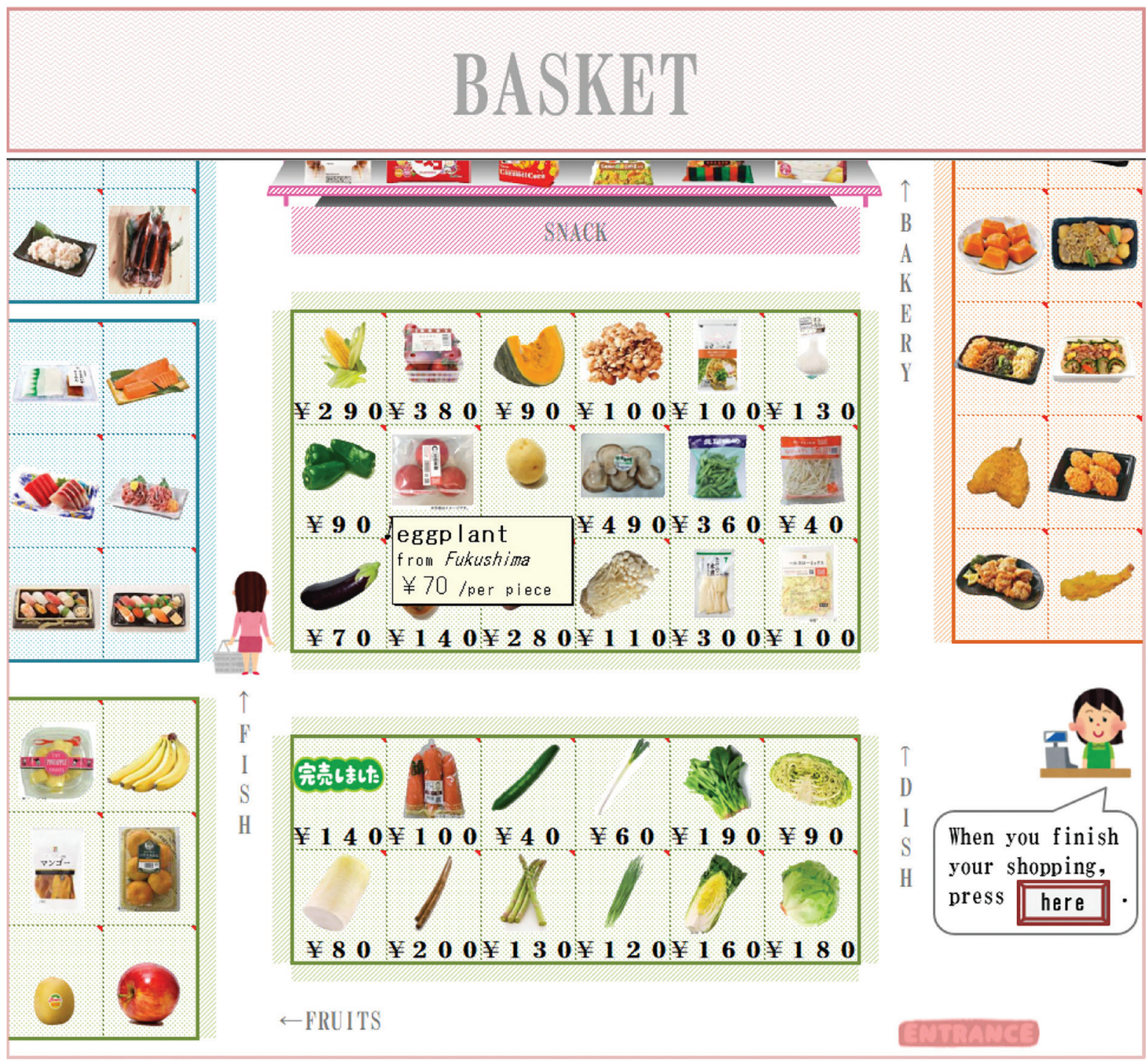

Figure $1 \mid$ The structure of Shopping Game

[In front of beverage area] I see ... oh, I want milk-X. milk ... My family like milk-X. We will not purchase the others. I know milk-X is more expensive than the others, but milk-Y is not better than milk-X ... meat ... [She gave up to purchase beef at meat area previously] I chose pork and saved my money. So I can spend my money on milk!

Figure 2 The utterances of participant (A)

activated utterances. In addition, a choice of milk was caused by a choice of meat. This participant showed her ability of budget management Participant (B) was house-worker and (C) was her daughter (Figure 3). They discuss which vegetables are good for yakisoba. In this case, they could not find a noodle for yakisoba in the end, so they planned to purchase a noodle at the other shop.

When our participants play the game, they showed some types of utterances/conversation. We summarized intellectual activities of our participants into Table 1. This game will be used as the following purposes. To prevent dementia, cognitive functions would be trained. In the future, evaluation of cognitive functions would be also added. The game would be useful to activate a communication. Otake said "The shortage of social communication is one of the main factor of dementia" [9]. So we plan to make a situation where some users can simultaneously play the game to communicate with each other.

\section{DISCUSSION - SHOPPING GAME WITH CONTENT GENERATION}

In the future, Shopping Game has to change its contents automatically depending on its user. Some functions will be added to the Shopping Game. From the viewpoint of cognitive training, out of stock and change of price are needed. In addition, it is good for user to be sometimes shown some special items with discount or with best season. Furthermore, other shoppers would influence on user 
B: What's best for our lunch? ... ok, let's cook yakisoba. First, I need green peppers ...

C: Why?? [She dislikes green pepper]

B: I also need a cabbage.

C: How about carrots?

B: Carrots remain in a refrigerator.

B: oh ... where is noodle [for yakisoba]?? This shop doesn't have one??

B: Now, let's drop in at Shop-P in our way to home. [She said to her daughter] Just remember it!

C: Shop-P?

B: Yes, I don't want to change my plan [to cook yakisoba]. If I do so, I should return all these vegetables to vegetable area. It's troublesome!!

Figure 3 The utterances of participants (B) and (C)

Table 1 A list of units observed in shopping activities

\begin{tabular}{|c|c|c|}
\hline Class & Symbol & Activity \\
\hline \multirow[t]{3}{*}{ Notice } & $n 1$ & To simply notice an item \\
\hline & $n 2$ & To find an item which a shopper wanted \\
\hline & $n c$ & $\begin{array}{l}\text { To notice an item which a shopper has } \\
\text { already noticed }\end{array}$ \\
\hline \multirow[t]{3}{*}{ Result } & $r+1$ & To put an item into a shopping cart \\
\hline & $r 0$ & Not to put an item into a shopping cart \\
\hline & $r-1$ & $\begin{array}{l}\text { To move an item from a shopping cart to a } \\
\text { selling zone }\end{array}$ \\
\hline \multirow[t]{5}{*}{ Search } & $s 1$ & To search some items in a store \\
\hline & $s 2$ & To search some items in a selling zone \\
\hline & $s 3$ & To notice or find a selling zone \\
\hline & $s 4$ & To arrive at a selling zone \\
\hline & $s 5$ & To move toward a checkout counter \\
\hline \multirow[t]{10}{*}{ Knowledge } & $k 1$ & Price or market price of an item \\
\hline & $k 2$ & Producing area of an item \\
\hline & $k 3$ & The best season for an item \\
\hline & $k 4$ & Freshness of an item \\
\hline & $k 5$ & Use of an item \\
\hline & $k 6$ & Characteristics of an item \\
\hline & $k 7$ & Family's preferences \\
\hline & $k 8$ & Arrangement in a store \\
\hline & $k 9$ & Stock in a store \\
\hline & $k 10$ & Evaluation on a store \\
\hline \multirow[t]{8}{*}{ Planning } & $p 1$ & To check a shopping cart \\
\hline & $p^{2}$ & $\begin{array}{l}\text { To check sequence during shopping } \\
\text { activities }\end{array}$ \\
\hline & p3 & To check a shopper's plan \\
\hline & $p 4$ & To consider a shopper's plan \\
\hline & $p 5$ & To adjust balance of items \\
\hline & p6 & To manage a shopper's budget \\
\hline & p7 & To recall stock in a shopper's house \\
\hline & p8 & To predict stock in a shopper's house \\
\hline \multirow[t]{4}{*}{ Idea } & $i 1$ & To compare an item with the others \\
\hline & $i 2$ & To combine an item with the others \\
\hline & $i 3$ & To use an item as other purpose \\
\hline & $i 4$ & To substitute an item for the other item \\
\hline
\end{tabular}

so some virtual shoppers which move automatically are needed in the virtual store.

Recently, healthy ageing has been an important concept to decrease risk of disease, care independence or any other troubles. For example, WHO has recommended healthy lifestyle to younger and middle-aged people. In addition, a concept "ME-BYO" which was originally generated in oriental medicine has been accepted around the world. This concept means inarticulate zone between health and disease and encourages healthy life style. So preventing dementia is the problem not only for the elderly but also for the young or middle-aged people. We have to enhance our game taking diversity of users into account.

\section{CONCLUSION}

In this paper, we constructed Shopping Game for healthy ageing and discussed how to evaluate the activities in the game from the viewpoint of preventing dementia. We conducted observations to determine if the shopping activities were really intelligent activities and we showed some examples of utterances/conversations in shopping activities. Our participants talked actively, for example, when they found their favorite items in a grocery store, when they complain about price and when they let the other participants know useful information. Accordingly, we think we can activate utterances/conversations if we give a topic about shopping to people in Shopping Game. In the future, we consider it will be also used for evaluation of cognitive functions so we have to make a criteria for users' performance.

\section{REFERENCES}

[1] M. Otake, Conversation support robot for promoting cognitive activity of older adults, J. Japanese Soc. Artif. Intell. 29 (2014), 591-598.

[2] Ministry of Health, Labour and Welfare, Healthy Japan 21 (Physical Activities and Sports), http://www1.mhlw.go.jp/topics/ kenko21_11/b2.html, 4/19/2015 reference, 2015 (in Japanese).

[3] The graph of people visiting convenient stores, http://www.garbagenews.net/archives/1953464.html, 2014 (in Japanese).

[4] S. Deterding, M. Sicart, L. Nacke, K. Ohara, D. Dixon, Gamification: using game-design elements in non-gaming contexts. Proceedings of the 2011 Annual Conference Extended Abstracts on Human Factors in Computing Systems (CHI EA'11), Vancouver, BC, Canada, 2011, pp. 2425-2428.

[5] J. Rosen, A. Turano, Stopwatch Marketing: Take Charge of the Time When Your Customer Decides to Buy, Emerald Group Publishing Limited, 2008.

[6] M. Matsushita, K. Hamatani, H. Nitto, Why don't Japanese people purchase commodity?, Toyo Keizai Inc, 2013.

[7] S. Abe, Shopping activities and information processing - a trial of protocol analysis, Yokohama Manage, Study 4 (1984), 33-48.

[8] The Mainichi, Shopping Refugees in Urban Areas, A Morning Edition of the Mainichi, 2014.

[9] M. Otake, Coimagination Method for Nursing Care, Chuohoki Publishing Co., Ltd., 2011. 


\section{Authors Introduction}

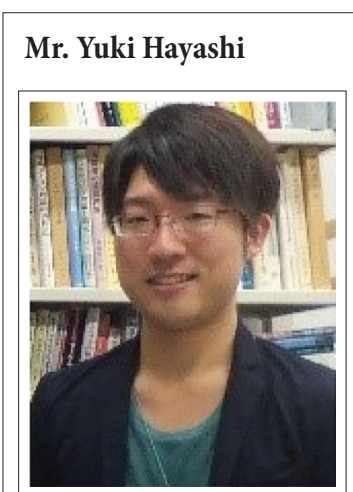

He graduated Master course at Humanities and Social Sciences of Chiba University in 2017. His main research interests are developmental psychology, cognitive science, narratology and human behavior and language. He is a member of IEEE, JSAI (The Japanese Society for Artificial Intelligence), JCSS (Japanese Cognitive Science Society), IPSJ (Information Processing Society of Japan) and CIHCD (The Society of Citizen Informatics for Human Cognitive Disorder).

\section{Dr. Akinori Abe}

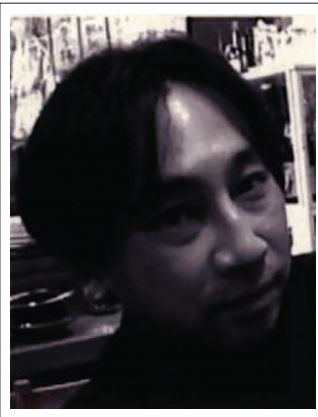

He received an M.E. and Doctor of Engineering $(\mathrm{PhD})$ from the University of Tokyo in 1988 and 1991 respectively. His main research interests are abduction, analogical reasoning, data mining, Chance Discovery and language sense processing (rather emotional aspects of language processing). He worked in NTT Communication Science Laboratories from 1991 to 2000, NTT MSC (Malaysia) from 2000 to 2002, and ATR from 2002 to 2009 . He also worked as an associate professor of IREIIMS, Tokyo Women's Medical University and a visiting associate professor of Kobe University Graduate School (Cooperation Course). In 2009 he returned to NTT Communication Science Laboratories. Then he moved to Faculty of Letters, Chiba University in April 2012. Since then he is a full professor of Chiba University. 